\title{
Sociodemographic Indicators for Substance Use and Abuse in Egypt
}

\begin{abstract}
Keywords: Substance use; Alcohol; Cannabis; Sociodemographic; Egypt

\section{Abstract}

Background: Addiction is a major problem in Egypt, due to rapidly growing and changing patterns of substance use. Identifying the socio-demographic characteristics of users may guide decision makers to plan for the eradication of this community problem.

Methods: A cross-sectional community-based survey of samples of the population by teams of trained clinical social workers. The survey was completed over 6 phases to cover 26 out of 27 Egyptian governorates (last 4 phases in 18 governorates are illustrated in this manuscript).

Results: A total of 106480 subjects were included in the sample representing approximately $0.2 \%$ the Egyptian population above the age of 15 . A proportion of $19.3 \%$ were experimental users, $6.7 \%$ were regular on substance use, while $6.4 \%$ were fulfilling the criteria of dependence. Significant associations were found between substance use and gender, age, residence, education, occupation, and marita status.

Conclusion: There are considerable regional variations in the overall rates of substance use/abuse in Egypt. However, the demographic risk factors are remarkably consistent across regions with only minor differences. Substance use and abuse have higher lifetime prevalence among young and middle aged males, less educated persons, working in technical or commercial jobs, with failed marriage, and living in urban areas.
\end{abstract}

\section{Introduction}

Many countries around the world have established national programs for regular monitoring of the rates of substance use and abuse within their borders and how these rates change over time. In Egypt and since the 1970's there has been a sudden increase of drug use. Illicit substance use/abuse continues to cause societal and national concern for good reasons. Several reports have been published and several local surveys have been conducted [1-3]. All seem to have suffered a problem with small numbers and/or a focus on certain groups, within a community [4-16]. The true prevalence of substance use and abuse in a satisfactory random sample of the whole population is still unknown. This ultimate aim requires considerable ingenuity and resources to overcome underreporting of this prevalent but illusive phenomenon.

Egypt started a National Addiction Research Program as early as 1994 funded by the government and led by the Ministry of Health. The first report of the Program entitled "National Research on Addiction" was published in Arabic [17]. It revealed that $6.2 \%$ of the population declared using substance(s) of abuse at least once.

Epidemiological research and clinical studies showed that the

\section{Journal of}

\section{Addiction \& Prevention}

Emad Hamdi ${ }^{1}$, Noha Sabry ${ }^{1}$, Albert Sedrak ${ }^{1}$, Aref Khowailed $^{1}$, Nasser Loza ${ }^{1}$, Menan Rabie ${ }^{2^{*}}$ and Hisham Ramy ${ }^{2}$

${ }^{I}$ General Secretariat of Mental Health and Addiction treatment (GSMHAT), MOH, Cairo University, Egypt ${ }^{2}$ Institute of Psychiatry, Ain Shams University, Cairo, Egypt

\section{*Address for Correspondence}

Menan A. Rabie, Institute of Psychiatry, Ain Shams University hospitals, 22 der elmalak, Abbassia, PO Box: 11657, Cairo, Egypt, Tel: +201005758864; Fax: +20226836379; E-mail: menan74@yahoo.com

Submission: 28 October, 2015

Accepted: 18 April, 2016

Published: 22 April, 2016

Copyright: () 2016 Hamdi E, et al. This is an open access article distributed under the Creative Commons Attribution License, which permits unrestricted use, distribution, and reproduction in any medium, provided the original work is properly cited.

rate of experimentation' with drugs was about $10-12 \%$ in the age group 15-25 years; the rate for drug 'misuse' was $2.5-3 \%$, whereas those identified as drug 'addicts' would constitute less than $1 \%$ of the population (65 million in 1998). Such alarming estimates constituted a warning to policymakers and service providers [18].

In 2001, the scene in Egypt was characterized by an unprecedented shift towards 'demand reduction' at the primary prevention level, hand in hand with efforts to provide services at both secondary and tertiary health care levels. Supply control mechanisms were duly and seriously implemented [3].

The second report of the "National Addiction Research Program" was issued in 2005 in Arabic language. It revealed that $12.6 \%$ of the population was regular users. These findings shed light on the increasing impact and severity of the problem of substance abuse in the country [19]. Prevalence seems to have doubled in 9 years. The reports mentioned above could not be included in the current study due to methodological differences.

Sporadic Research has been conducted for three decades to study the Addiction problem in Egypt. Several Published papers studied special population subgroups, mostly students. None of them surveyed a sufficient community sample in which all population subgroups were represented [20-23]. Globally, it is estimated that in 2012, between 162 million and 324 million people, corresponding to between 3.5 per cent and 7.0 per cent of the world population aged 15-64, had used an illicit drug - mainly a substance belonging to the cannabis, opioid, cocaine or amphetamine-type stimulants group - at least once in the previous year. The extent of problem drug use - by regular drug users and those with drug use disorders or dependence remains stable at between 16 million and 39 million people [24].

The Egyptian census in 2015 was $87,963,276$ people [25]. The current study revealed that about one fifth (19.1\%) of the studied sample are regularly using substance (tobacco smoking was excluded). 
Citation: Hamdi E, Sabry N, Sedrak A, Khowailed A, Loza N. Sociodemographic Indicators for Substance Use and Abuse in Egypt. J Addiction Prevention. 2016;4(1): 8

These findings show the need to raise the awareness of policy makers to the importance of detecting the actual status of substance abuse problems, and the significance of developing future prevention programs for Addiction.

Since 2007 to 2014, the Unit of Research in the General secretariat of Mental Health and Addiction Treatment, Ministry Of Health, Egypt, has been conducting a survey to study the substance abuse problem in the Egyptian governorates. A total number of 106480 adult Egyptians were included in the survey.

\section{Aim and Objectives}

"The National Addiction Research Program in Egypt" aimed to study the current prevalence of substance use and abuse in a community sample, and to determine the current status of the problem, through sufficient reliably collected data. The long term final aim is to collect reliable and valid data to provide a solid base for management and prevention of the substance abuse problem in the country.

\section{Design and Method}

"The National Addiction Research Program in Egypt" is an ongoing cross-sectional descriptive community-based study, performed sequentially by teams of trained researchers in all Egyptian governorates. Since 1994 till 2014, the National Addiction Research Program covered 26 out of 27 Egyptian governorates with the exception of the Western Sahara governorate of The New Valley (El-Wadi El-Gedid) which is one of the least populated Egyptian governments $(2,25,416$ people in 2015) (Figure 1). This manuscript deals with the findings from the last 4 phases: Delta and middle regions (8 governorates) [26]; Cairo (the capital) [27]; Egypt's coastal regions (4 governorates); and southern Egypt (5 governorates) $[28,29]$. Trained researchers individually interviewed a sample of the population from each locale using the same research instrument.

\section{Sample Selection}

The samples for this study were selected from the Egyptian adult population (16 years and older). The population size and demographic characteristics of each governorate was determined from the national census [30]. The target number of subjects from each governorate was defined, according to the population size to include around $0.2 \%$ of the general population. The sample was pre-defined in terms of drawing a number of subjects from different strata of the population: males and females; young, middle and old age groups; students, doctors, teachers, housewives and persons from trade and skilled workers, etc,. Data collection was accomplished through direct interviewing in randomly chosen geographical areas dedicated to researchers.

\section{Training}

Each group of researchers was recruited from the clinical social workers within the $\mathrm{MOH}$ regional directorate. The local group was led by a senior member, and a local committee facilitated the study implementation and logistics. Researchers were trained to approach individuals, identifying themselves and the purpose of the study. After obtaining a written informed consent and reassuring the subject about anonymity they proceeded with the study questionnaire which took around 20 minutes. At the end of the questionnaire they were required to record and place the interviewee on a continuum of substance use. All researchers were given intensive training about the questions relevant to identifying the level of drug use and the basis for formulating their decision.

Training involved going step by step through the questionnaire identifying how the choices should be scored. This was followed by assessments of mock cases, group scoring, and reflection to achieve consensus. A team of around 20-30 researchers was trained from each governorate. This allowed the assessment of 200-300 subjects for each individual researcher.

\section{Research Instrument}

The study questionnaire is a designed questionnaire based upon the Addiction severity index with modifications to match Egyptian cultural and social characteristics [31]. The questionnaire is multi

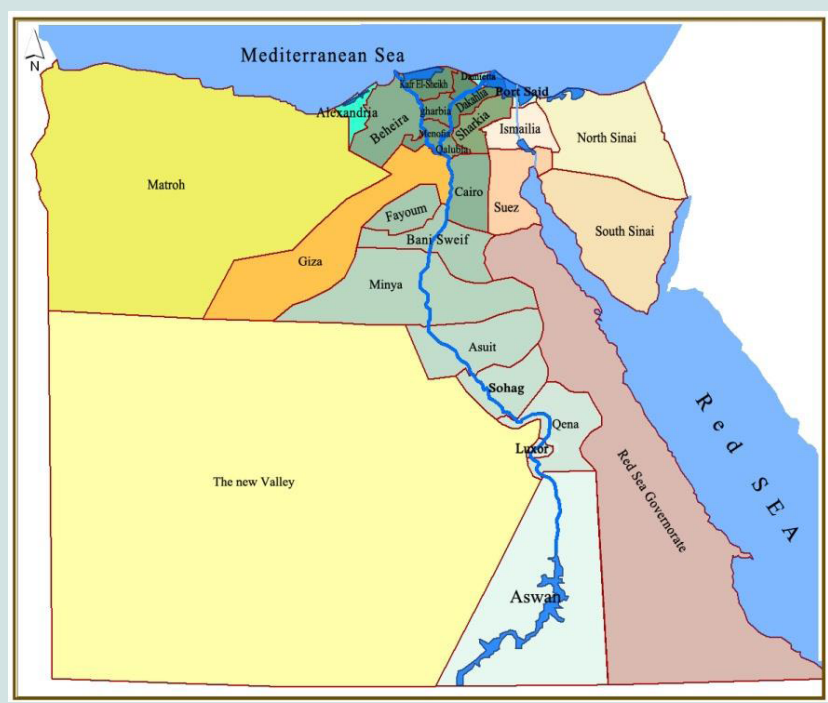

Figure 1: Map of Egypt showing the country governorates. 
Citation: Hamdi E, Sabry N, Sedrak A, Khowailed A, Loza N. Sociodemographic Indicators for Substance Use and Abuse in Egypt. J Addiction Prevention. 2016;4(1): 8

ISSN: $2330-2178$

dimensional covering demographic information, information about social situation and upbringing, smoking, drinking and drug use history, attitude towards drug use, prevalent cultural misconceptions about drug use, and views on the origins of any illicit drug use. It also includes detailed questions distinguishing experimental or recreational drug use from regular use and the abuse/addiction continuum. The researcher applied the questionnaire individually after an introduction and informed consent which explained the study procedure and guaranteed the confidentiality of personal data.

The study questionnaire is a quantitative tool consisting of around 70 questions with pre-determined multiple-choice answers. It has been thoroughly revised without a change of basic questions during the 4 phases of the research to reach a multidimensional detailed tool capable of assessing the multifaceted problem of substance use and abuse. Feedback from the researchers during the pilot study was an important input to clarify questions and give more precise wording of answers.

\section{Operational definitions}

Experimental users: These are the persons who tried the use of substance(s) once or several times but are neither regular nor dependent

Regular users: These are the persons who are continuously and habitually using substance(s) almost daily for duration more than one month.

Dependence: According to the DSM-IV criteria for alcohol dependence, at least three out of seven of the following criteria must be manifest during a 12-month period: Tolerance, Withdrawal symptoms, Use in larger amounts or for longer periods than intended, Persistent desire or unsuccessful efforts to cut down on alcohol use, Time is spent obtaining alcohol or recovering from effects, Social, occupational and recreational pursuits are given up or reduced because of alcohol use, Use is continued despite knowledge of alcohol-related harm (physical or psychological).

\section{Pilot Study}

The research questionnaire was applied to 200 subjects from each governorate. The resulting data were collected and revised. The subsequent recommendations were discussed with the team members, to improve the performance and the application process.

\section{Ethical Considerations}

The study protocol was approved by The Ethical Committee of the General Secretariat of Mental Health and Addiction treatment (GSMHAT), MOH. A written informed consent was obtained from all the participants after the explanation of the procedures and the objectives of the study.

\section{Data Entry and Analysis}

Each questionnaire went through a local revision for completeness of data. A central revision process was focused, in addition, on data internal consistency. Data was subsequently entered on SPSS spreadsheets for each governorate. Double entry was performed in 2007 to check the equivalence and accuracy of the process. Spot checks were executed during data entry and on the combined spreadsheet after completion.

Basic forms of statistical analysis were reported in this study. The data is statistically represented quantitatively as means and standard deviation for the continuous variables, which were further analyzed by the use of Student $\mathrm{t}$-test. Categorical variables were represented as percentages and were further analyzed by the use of Chi square.

The results of the variables were illustrating the prevalence, intensity and descriptive details about the alcohol and substance use, and were correlated to sociodemographic variables.

Because of the large numbers of subjects involved, statistical significance has been set at $\mathrm{P}$-value $<0.001$.

\section{Results}

This study was supposed to be applied on a number of 115107 persons. A total of 4642 questionnaires were incomplete or included inconsistent information, and therefore were excluded. Meanwhile, a number of 3985 persons refused to participate in the study. Finally the study was performed on 106480 Egyptian subjects, a large community sample representing the adult Egyptian population.

Most of the sample was from the age group (26-35 years old) $20.6 \%$ with a male preponderance in all phases, i.e. $67.5 \%$ of the whole sample were males. The ratio between males : females was about $7: 1$, (13:1 in Delta, 2.7:1 in Cairo, 7:1 in Coastal regions, 5:1 in Upper Egypt). Age groups are illustrated in Table 1.

As regards the used substances, Cannabis was the commonest in all regions. In total, $77 \%$ of the substance users were using Cannabis. Alcohol (28.6\% of total use) was the $2^{\text {nd }}$ common substance of use in all Egyptian governorates, except in Upper Egypt (where the opiates were commoner than alcohol). Meanwhile, in governorates outside the Upper Egypt, opiates were the $3^{\text {rd }}$ common substance of use in Egypt (23.4\% of total use). The pharmacological agents (14.6\%), the stimulants $(1.9 \%)$ and the organic solvents $(1.5 \%)$ are following in frequency, respectively (Table 2).

As regards the pattern of use, $13.3 \%$ used substance once in their lives, $6.0 \%$ were experimental users, and $6.7 \%$ are regular on substance use, while, $6.4 \%$ were fulfilling the criteria of dependence (Tables 3 and 4).

There was a highly significant difference between both genders as regards the use of substance, $15.8 \%$ of the sample were male substance users while $2.2 \%$ were female substance users. About $36 \%$ of the males living in Cairo were using substance(s). The percentage was relatively

Table 1: Age group distribution in the sample.

\begin{tabular}{|c|c|c|c|c|c|}
\hline Phase & Delta & Cairo & Coasts & $\begin{array}{l}\text { Upper } \\
\text { Egypt }\end{array}$ & Total sample \\
\hline $16-19$ & \multirow{2}{*}{20800} & 5445 & 1830 & 3751 & \multirow{2}{*}{45303} \\
\hline $20-25$ & & 8541 & 2215 & 2721 & \\
\hline $26-35$ & 7293 & 8910 & 2697 & 3079 & 21979 \\
\hline $36-45$ & 6092 & 8031 & 2540 & 2867 & 19530 \\
\hline $46-55$ & 3939 & 5446 & 1766 & 2561 & 13712 \\
\hline $56-65$ & \multirow{2}{*}{1192} & 1714 & 419 & 923 & \multirow{2}{*}{4957} \\
\hline$>65$ & & 327 & 120 & 262 & \\
\hline Unknown & 767 & 194 & 16 & 22 & 999 \\
\hline Total & 40083 & 38608 & 11603 & 16186 & 106480 \\
\hline
\end{tabular}


Citation: Hamdi E, Sabry N, Sedrak A, Khowailed A, Loza N. Sociodemographic Indicators for Substance Use and Abuse in Egypt. J Addiction Prevention. 2016;4(1): 8

ISSN: $2330-2178$

Table 2: Type of substances used in the Egyptian regions.

\begin{tabular}{|c|c|c|c|c|c|c|c|c|c|c|c|}
\hline & \multicolumn{2}{|c|}{$\begin{array}{l}\text { Delta and middle } \\
\text { regions }\end{array}$} & \multicolumn{2}{|c|}{ Cairo } & \multicolumn{2}{|c|}{ Coastal regions } & \multicolumn{2}{|c|}{ Upper Egypt } & $\begin{array}{c}\begin{array}{c}\text { Total } \\
\text { number }\end{array} \\
\#\end{array}$ & $\begin{array}{c}\text { Percentage } \\
\text { to general } \\
\text { population } \\
\quad \%\end{array}$ & $\begin{array}{c}\text { Percentage } \\
\text { between } \\
\text { different } \\
\text { substances } \\
\%\end{array}$ \\
\hline Alcohol & 870 & $2.17 \%$ & 4088 & $10.59 \%$ & 574 & $4.95 \%$ & 757 & $4.68 \%$ & 6289 & $5.90 \%$ & $19.45 \%$ \\
\hline Cannabinoids & 3591 & $8.96 \%$ & 10037 & $26.00 \%$ & 1474 & $12.70 \%$ & 1834 & $11.33 \%$ & 16936 & $15.91 \%$ & $52.39 \%$ \\
\hline Opiates & 275 & $0.69 \%$ & 3501 & $9.07 \%$ & 418 & $3.60 \%$ & 945 & $5.84 \%$ & 5139 & $4.83 \%$ & $15.90 \%$ \\
\hline Stimulants & 202 & $0.50 \%$ & 176 & $0.45 \%$ & 13 & $0.11 \%$ & 22 & $0.14 \%$ & 413 & $0.39 \%$ & $1.28 \%$ \\
\hline Organic solvents & 12 & $0.03 \%$ & 276 & 0.71 & 19 & $0.16 \%$ & 25 & $0.15 \%$ & 332 & $0.31 \%$ & $1.03 \%$ \\
\hline Total users & 53991 & $13.47 \%$ & 20777 & $53.81 \%$ & 2537 & $21.86 \%$ & 3519 & $22.16 \%$ & 32329 & $30.36 \%$ & $100 \%$ \\
\hline Total sample & 40083 & $100 \%$ & 38608 & $100 \%$ & 11603 & $100 \%$ & 16186 & $100 \%$ & & & \\
\hline
\end{tabular}

\# is the number of persons who declared using the substance

Table 3: Pattern of substance use in relation to the general population in each region.

\begin{tabular}{|c|c|c|c|c|c|c|c|c|c|c|}
\hline & \multicolumn{2}{|c|}{ Delta and middle Regions } & \multicolumn{2}{|c|}{ Cairo } & \multicolumn{2}{|c|}{ Coastal Regions } & \multicolumn{2}{|c|}{ Upper Egypt } & \multicolumn{2}{|c|}{ Total } \\
\hline & $\#$ & $\%$ & $\#$ & $\%$ & $\#$ & $\%$ & $\#$ & $\%$ & $\#$ & $\%$ \\
\hline Once & 0 & $0 \%$ & 12779 & $33.1 \%$ & 1117 & $9.63 \%$ & 286 & $1.77 \%$ & 14182 & $13.32 \%$ \\
\hline Experimental & 1329 & $3.32 \%$ & 3760 & $9.74 \%$ & 526 & $4.53 \%$ & 771 & $4.76 \%$ & 6386 & $5.99 \%$ \\
\hline Regular & 1860 & $4.64 \%$ & 4115 & $10.66 \%$ & 557 & $4.80 \%$ & 592 & $3.66 \%$ & 7124 & $6.69 \%$ \\
\hline Dependence/ abuse & 629 & $1.57 \%$ & 4184 & $10.84 \%$ & 555 & $4.78 \%$ & 1438 & $8.88 \%$ & 6806 & $6.39 \%$ \\
\hline Total & 40083 & $100 \%$ & 38608 & $100 \%$ & 11603 & $100 \%$ & 16186 & $100 \%$ & 106480 & \\
\hline
\end{tabular}

\# is the number of persons who declared using the substance

Table 4: Regional differences in the pattern of substance use in Egypt.

\begin{tabular}{|c|c|c|c|c|c|c|c|c|c|c|}
\hline & \multicolumn{2}{|c|}{ Delta and middle Regions } & \multicolumn{2}{|c|}{ Cairo } & \multicolumn{2}{|c|}{ Coastal Regions } & \multicolumn{2}{|c|}{ Upper Egypt } & \multicolumn{2}{|c|}{ Total } \\
\hline & $\#$ & $\%$ & $\#$ & $\%$ & $\#$ & $\%$ & \# & $\%$ & $\#$ & $\%$ \\
\hline Once & 0 & $0 \%$ & 12779 & $90.11 \%$ & 1117 & $7.87 \%$ & 286 & $2.02 \%$ & 14182 & $100 \%$ \\
\hline Experimental & 1329 & $20.81 \%$ & 3760 & $58.88 \%$ & 526 & $8.24 \%$ & 771 & $12.07 \%$ & 6386 & $100 \%$ \\
\hline Regular & 1860 & $26.11 \%$ & 4115 & $57.76 \%$ & 557 & $7.82 \%$ & 592 & $8.31 \%$ & 7124 & $100 \%$ \\
\hline Dependence/ abuse & 629 & $9.24 \%$ & 4184 & $61.48 \%$ & 555 & $8.15 \%$ & 1438 & $21.13 \%$ & 6806 & $100 \%$ \\
\hline Total & 40083 & $37.64 \%$ & 38608 & $36.26 \%$ & 11603 & $10.90 \%$ & 16186 & $15.20 \%$ & 106480 & \\
\hline
\end{tabular}

\# is the number of persons who declared using the substance

high in Upper Egypt (27.3\%) and less in north and East Coast, and in Delta (14.3\%, and $13.2 \%$, respectively). As regards females, $13.9 \%$ of females living in Cairo, 5.5\% of those living in Upper Egypt, $2.8 \%$ of those living in Coastal governorates, and $1.1 \%$ of those living in Delta were using substance(s).

A percentage of $15.8 \%$ of young people aged (16-25) were using substance(s). The group of young adults was the most represented age group among substance users $(6.6 \%$ of the sample was aged between 16 and 25 years). Nevertheless, the adult age groups (26-35; 36-45) showed a relatively high representation among the users $(4.8 \%$ and $4.1 \%$ of the whole sample, respectively).

As regards the regions of residence, most substance users were living in urban areas (4.7\%). Most Bedouins living in Delta and Upper Egypt were using substance(s). People of rural origins (29.3\%) were the least at using substance(s) (Table 5).

The association with lower education was highly significant, the less educated people were more common users of substance(s): $34.2 \%$ of those graduated from primary school, $25.1 \%$ of illiterate persons,
$23.2 \%$ of those graduated from preparatory school and $22.8 \%$ of those who can barely read and write.

As regards the occupation, substance use and abuse was common among merchants $38.9 \%$, and among technicians $37.6 \%$. Marital status was also significantly correlated to substance use and abuse. It was of the highest prevalence among those married twice (30.9\%), and those who were divorced $(25.7 \%)$.

\section{Discussion}

Developing countries (including Egypt) are somehow delayed at acquiring accurate statistics about the phenomenon of drug use. In this study, there have been several attempts at ensuring the reliability and validity of data collection and processing. The process of training the researchers included several steps at checking the authenticity of information supplied by the interview (validity) and several training steps to ensure that the reliability between researchers is high. This study though did not report a separate inter-researcher reliability study because of the large number of researchers involved in each stage. The questionnaire was however, structured in a way such that 
Citation: Hamdi E, Sabry N, Sedrak A, Khowailed A, Loza N. Sociodemographic Indicators for Substance Use and Abuse in Egypt. J Addiction Prevention. 2016;4(1): 8

ISSN: $2330-2178$

Table 5: Regional variations in relationship between substance use (ever used) and residence.

\begin{tabular}{|c|c|c|c|c|c|c|c|c|}
\hline & \multicolumn{2}{|c|}{$\begin{array}{c}\text { Delta and } \\
\text { middle regions }\end{array}$} & \multicolumn{2}{|c|}{ Coastal Regions } & \multicolumn{2}{|c|}{ Upper Egypt } & \multicolumn{2}{|c|}{ Total } \\
\hline & $\#$ & $\%$ & $\#$ & $\%$ & $\#$ & $\%$ & $\#$ & $\%$ \\
\hline Urban & 2310 & $10.6 \%$ & 882 & $8.3 \%$ & 1812 & $17.6 \%$ & 5004 & $4.7 \%$ \\
\hline Rural & 1400 & $7.9 \%$ & 53 & $9.5 \%$ & 1360 & $21.7 \%$ & 2813 & $2.6 \%$ \\
\hline Bedouin & 38 & $30.5 \%$ & 168 & $16.1 \%$ & 3 & $37.5 \%$ & 209 & $0.2 \%$ \\
\hline Chi square & \multicolumn{2}{|c|}{48.379} & \multicolumn{2}{|c|}{47.5} & \multicolumn{2}{|c|}{45} & & \\
\hline$p$-value & \multicolumn{2}{|c|}{0.0001} & \multicolumn{2}{|r|}{00} & \multicolumn{2}{|c|}{.0001} & & \\
\hline
\end{tabular}

all the responses were interviewee dependent with no value judgments given by the interviewer.

This report offers convincing evidence about the demographic correlates of substance use in Egypt. The conviction is derived from the large sample sizes employed at all stages, from the coverage of the sample of all regions of Egypt, and from the fact that the statistically significant demographic associations are repeated and replicated in all stages.

This manuscript describes the effort performed by the whole research team of the Mental Health Secretariat of the Ministry of Health, to achieve a nationwide Egyptian study. This was achieved through directly interviewing a number of 106480 adult Egyptians, during the 4 phases of the research which was realized over the last 8 years (2007-2014). By virtue of the addiction research program design, the sample does not represent the population composition of Egypt. It is positively skewed towards sampling more males, younger persons, and those in schooling or university education [32].

Despite the efforts of the government and the NGOs to control the substance use, this problem is becoming more prevalent with time. As regards the pattern of use, $19.3 \%$ were experimental users (of them 13.3\% used substance once in their lives), and 6.7\% were regular on substance use, while, $6.4 \%$ were fulfilling the criteria of dependence. These findings shed light on the impact of such a problem on the Egyptian society. About one fifth $(19.1 \%)$ of the Egyptians were dealing regularly with substance(s). While during the year 2001, an epidemiological research and clinical studies of known addicts showed that the rate of 'experimentation' with drugs was about $10-12 \%$ in the age group 15-25 years; the rate for drug 'misuse' would be $2.5-3 \%$ whereas those identified as drug 'addicts' would constitute less than $1 \%$ of the population (65 million in 1998) [33] . The percentage of substance users has almost doubled in 13 years.

The commonly used substances were found to be in the following order: Cannabis was the commonest in all regions. In total, 52.39\% of the substance users were using Cannabis which represents $15.91 \%$ of the sample. This was consonant with the rates of cannabis use in North Africa which was found to be $4.3 \%$ of the General Population [24].

Alcohol was the $2^{\text {nd }}$ common substance of use in all Egyptian governorates (5.9\% of the sample), except in Upper Egypt, where the opiates $(5.84 \%)$ were more commonly used than alcohol (4.68\%). This was not consistent with the UNODC 2014 World Drug Report which states that the use of opiates in north Africa is as little as $0.2 \%$ of the general population [24]
An international report announced an increase in the use of alcohol in several Muslim countries, which usually prohibit the use of alcoholic beverages capable of changing behavior. Between the years 2005, and 2010, the average consumption by these countries increased by $25 \%$ from 11.7 billion to 15.2 billion liters. During the 5-year survey period the Turks increased from 18.3 to 20.5 liters per person, UAE citizens from 30.4 to 36.8 liters [34].

In Algeria, where alcohol is not prohibited except during Ramadan (6.8 liters per year per person in 2010), consumption increase by $7 \%$ in terms of value and $3 \%$ in volume. In Saudi Arabia and in Iran, where the prohibition is official and severe, people drink alcohol free beer. In Iran figures increased by $40 \%$ per year, from 61.9 million liters in 2005 to 338.7 million in 2010 [34].

As regards the sociodemographic description of the sample, the study revealed the following: The male gender was positively correlated (with high significance) to the use of substance(s), (15.8\% males versus $2.2 \%$ females). The ratio between males : females is about 7:1, (13:1 in Delta and middle Egypt governorates, 2.7:1 in Cairo, 7:1 in Coastal region governorates, 5:1 in Upper Egypt governorates). These ratios may be explained by a theory that the females are suffering more than males from internalizing problems (anxiety, and depression), while the males are suffering more than females from externalizing problem (substance use and aggression) [35]. In their study, Colpaert et al also found that the patients using alcohol and other illicit substances were characterized by a remarkably low percentage of women (17.5\%) [36].

The finding that the females from Cairo are more commonly suffering from substance use than the other regions of Egypt, may be explained in a cultural context by the openness of the female social life in Cairo, which implies more stresses on the females living there, and also makes it easy for them to reach the drug dealer areas. This is in concordance with an American research postulating that the differences in substance abuse, especially Cannabis between males and females, are decreasing markedly [37].

Higher levels of freedom of expression that women experience in Cairo may also enhance the willingness to disclose such a problem to the research team, in contrast to the shame and stigma a woman in rural area would encounter if she discloses a similar problem. Another major concern is the rise in tobacco use by young school girls, because those who start as children find it hardest to quit [38].

The group of young adults was the most represented age group among substance users (6.6\% of the sample was aged between 16 and 25 years). This is the most vulnerable age group due to characteristic problems of late adolescence/young adulthood and the significant peer influence and pressure, in addition to family history of substance use.

The current study showed that substance abuse is more common in the age group (26-35), i.e. $23.7 \%$ of the young people at this age group are using substance(s). The same relatively high percentage was encountered in the older age groups: $22.7 \%$ of middle aged people (36-45 years old), and $20.4 \%$ of those aged (46-55 years). These are supposed to be the most actively productive age groups, involved in the development of the country power. 
Citation: Hamdi E, Sabry N, Sedrak A, Khowailed A, Loza N. Sociodemographic Indicators for Substance Use and Abuse in Egypt. J Addiction Prevention. 2016;4(1): 8

However, the young adults aged (16-25) showed $15 \%$ percentage of substance use among their age group. This also may point that life stresses and adjustment difficulties, common at these age groups may play a role in the initiation and potentiation of the problem of substance use and abuse. This is consistent with the rates of Marijuana use in the American 10th and 12th grade students which were $(29.8 \%$ and $36.4 \%$ respectively) in 2013 [39].

Nevertheless, the adult age groups $(26-35 ; 36-45)$ showed a relatively high representation among users. Substance use was most common among merchants 38.9\%, and among technicians 37.6\%. These findings are probably related to the lower education and lower socioeconomic class of the people practicing these occupations, together with the relatively high income which is directed to the use of substance instead of other useful activities. Also these occupations are more susceptible for irregular incomes, losses, financial and social insecurity, which poses more stresses on this special population. Another study found different results: persons using substance are more often unemployed in more than one third of the cases [36].

The current study showed also that the less educated people were more common users of substance(s): $34.2 \%$ of those graduated from primary school, $25.1 \%$ of illiterate persons, $23.2 \%$ of those graduated from preparatory school and $22.8 \%$ of those who can barely read and write. The same was found in USA: In 2014, annual prevalence of use of any illicit drug was $39 \%$ for college students and $44 \%$ among the non college respondent [39]. These results may support the assumptions that education is a protective factor from substance abuse.

The association of the marital status to the substance use showed significant results. It showed the highest prevalence among those married twice $(30.9 \%)$, which points to a probable relationship between an unstable marriage and the substance use and abuse either as a cause or an effect. The problem of substance use was also high among those who are divorced or separated (25.7\%). However the causal relationship is difficult to determine. However, metaanalytic reviews of randomized clinical trials have concluded that, in comparison to interventions that focus exclusively on the substanceabusing patient, both alcoholism and drug abuse treatments that involve family result in higher levels of abstinence [40].

The causal connections between substance use and relationship discord are complex and reciprocal. Couples in which one partner abuses drugs or alcohol usually also have extensive relationship problems, often with high levels of relationship dissatisfaction, instability and verbal and physical aggression [41]. Relationship dysfunction in turn is associated with increased problematic substance use and post treatment relapse among alcoholics and drug abusers [42]. Thus, as shown in the "destructive cycle" segment of the figure, "Reversing a destructive cycle through behavioral couples therapy," substance use and marital problems generate a destructive cycle in which each induces the other. [43].

Association of the substance use and abuse and the regions of origin showed that most substance users were coming from urban areas $(4.7 \%)$. These areas are usually crowded, polluted and unattended by the care givers. Another interesting finding is that most Bedouins living in Delta and Upper Egypt are using substance(s). This may be explained by the fact that the Bedouin regions are accessible for drug cultivation and drug deals, due to issues related to security and surveillance.

People of rural origins (29.3\%) are the least at using substance(s). This is probably related to the stronger family bonds and social relations in the country side, and the difficulty to isolate and hide people suffering from substance use and abuse, for fear of stigma. Together, national and provincial data indicate that students who attend schools in rural settings are at increased likelihood of reporting certain outcomes related to substance use, predominantly those pertaining to alcohol use and associated risk behaviours [44].

To conclude, within Egypt, there is a significant regional variation in the rates of substance misuse. The relatively high rate of substance abuse in coastal areas is probably due to the fact that these areas are transit points for drug trafficking. Substance use is highest in the coastal cities of Suez and Alexandria, followed by Sharkia. Egypt's geographic location makes it a potential transit point between major illicit drug production areas in Asia and European markets. There also seems to be a significant cultivation of cannabis in the Sinai Peninsula passing to the rest of Egypt through Sharkia, Ismailia, and Suez [45]. Local cannabis production and the nomadic tribal lifestyle of people with Bedouin origins may explain the high rate of substance use detected in this group. However, this latter finding is not robust due to the small number of Bedouin subjects included in the study [32].

Finally the results of this study attract the scientific attention towards the real status of the substance use and abuse problem in Egypt. The preventive services should be mainly directed towards young and middle aged males, less educated persons, working in technical or commercial jobs, with failed marriage, and living in urban areas (especially Cairo and Upper Egypt).

\section{Significant Outcomes}

(i) This is considered as the first nation-wide study in Egypt covering all of the geographical regions, and all the cultural groups characterizing the country. The National Addiction Research Program started since the 1990s, but its reports were published only in Arabic Language. This will be the first publication in English language.

(ii) There are considerable regional variations in the overall rates of substance use/abuse in Egypt. However, the demographic risk factors are remarkably consistent across regions with only minor differences.

(iii) Substance use and abuse have higher lifetime prevalence among young and middle aged males, less educated persons, working in technical or commercial jobs, with failed marriage, and living in urban areas.

(iv) Substance use and abuse (Cannabis) is increasingly found in women especially in the Capital "Cairo".

(v) This report offers very convincing evidence about the demographic correlates of substance use in Egypt. The conviction is derived from the large sample sizes employed at all stages, from the coverage of the sample of all regions of Egypt, and from the fact that the statistically significant 
Citation: Hamdi E, Sabry N, Sedrak A, Khowailed A, Loza N. Sociodemographic Indicators for Substance Use and Abuse in Egypt. J Addiction Prevention. 2016;4(1): 8

ISSN: $2330-2178$

demographic associations are repeated and replicated in all stages.

\section{Limitations}

Although the study is revealing clinically interesting findings, however, there are some methodological limitations that need to be reported:

(i) The interview process did not guarantee privacy or $100 \%$ confidentiality to the interviewee. American and European surveys employ computers used by the interviewees to enter anonymously their information. Beside cost, this has not been possible to date with Egypt's National Addiction Research Program because of significant illiteracy among Egyptians.

(ii) The overall population prevalence rate derived from the method of sampling used in this research can be spuriously high. We would therefore caution against extrapolating overall prevalence rates in Egypt from the data reported here. The sample of the study is not a representative sample.

\section{References}

1. Soveif M, El-Sayed AM, Honnovrah MA, Darweash ZA (1979) The nonmedical use of psychoactive substances among secondary school male students in Egypt: An epidemiological study (a brief report). Egypt J Psychiatry 2: 198-204.

2. Okasha A (1985) Young people and the struggle against drug abuse in the Arab countries. Bull Narc 37: 67-73.

3. El-Akabawi AS (2001) Drug abuse in the Arab world: a country profile Egypt In: Okasha A, Maj M, (eds) Images in psychiatry: an Arab perspective, WPA series, Scientific Book House for Publishing \& Distributing, pp. 143-150.

4. Okasha A, Kamel M, Khalil AH, Bishry Z, Lotaief F, et al. (1982) Drug abuse among Egyptian University students: a comparison between succeeders and failures. Egypt J Psychiatry 5: 59-70.

5. Soueif MI, El-Sayed AM, Darweesh ZA, Hannourah MA (1982) The extent of non medical use of psychoactive substances among secondary school students in Greater Cairo. Drug Alcohol Depend 9: 15-41.

6. Soueif MI, Darweesh ZA, Hannourah MA, El-Sayed AM, (1982) The non medical use of psychoactive substances by male technical school students in Greater Cairo. an epidemiological study. Drug Alcohol Depend 10: 321-331.

7. Soueif MI, Darweesh ZA, Hannourah MA, El-Sayed AM, Yunis FA, et al (1986) The extent of drug use among Egyptian male university students. Drug and Alcohol Depend 18: 389-403.

8. Shaheen D, Abdel Mohsen Y, Ahmed M (1986) Changes in patterns of drug dependency in the last five years (1979-1984). Bull Narc 38: 16-23.

9. Wahdan N (1986) Social and economic effects of the phenomenon of spread of narcotic in Egypt. National Institute for Planning. Social and culture planning Center and Police Research centre.

10. Soueif MI, Hannourah MA, Darweesh ZA, el-Sayed AM, Yunis FA, et al. (1987) The use of psychoactive substances by female Egyptian university students, compared with their male colleagues on selected items. Drug Alcohol Depend 19: 233-247.

11. Soueif MI, Yunis FA, Youssuf GS, Moneim HA, Taha HS, et al. (1988) The use of psychoactive substances among the Egyptian males working in manufacturing industries. Drug Alcohol Depend 21: 217-229.

12. El-Mossalami MA, Saleh ZA, Kareem MA, Hamed MA (1988) Preliminary study on drug dependency determinants. The Egyptian journal of community Medicine 4: 89-97.

13. Soueif MI, Youssuf GS, Taha HS, Moneim HA, Sree OA, et al. (1990) Use of psychoactive substances among male secondary school pupils in Egypt: a study on a nationwide representative sample. Drug Alcohol Depend 26:
63-79.

14. Okasha A, Khalil AH, Fahmy M, Ghanem MH (1990) Psychological understanding of Egyptian Heroin users. Egypt J Psychiatry 13: 37-49.

15. El-Mahallawi N, El-Dawla AS (1992) Familial risk factors in substance use disorders. Egypt J Psychiatry 15: 10-16.

16. Demerdash A, Fathi A, Ibrahim AR, El-Tohamy S, Omran S (1992) Substance non-medical use among secondary school students in Assiout city. Egypt $J$ Psychiatry 15: 155-162.

17. Rakhawy YT, Ewaida M, El-Kott S, Faheem A, Abdulwahab MM, et al. (1996) The General Secretariat of Mental Health- $\mathrm{MOH}$ : the National Research on Addiction (use, abuse, dependency and addiction) preliminary report, $\mathrm{MOH}$.

18. Okasha A (2004) Focus on psychiatry in Egypt. Br J Psychiatry 185: 266-272.

19. Ghanem M (2005) The General Secretariat of Mental Health- MOH (2005): the yearly report of the General Secretariat of Mental Health- $\mathrm{MOH}$ about the rate of substance use.

20. Sadek A, El-Mahallawy N, Haroun El-Rasheed A, et al. (2002) Substance use disorders among female secondary school students in Cairo. The Egyptian Journal of Community Medicine 20.

21. Zaky S, El-Bahnasy R, Mahrous O, Al-Batanony M (2011) Epidemiology of substance abuse among secondary school children- Menoufiya governorate.

22. Mawaheb MA, El-Galad GM, Dawood AE, El-Sayed SH (2012) Drug abuse among students in (schools and colleges) in Fayoum city. MD thesis, Faculty of Medicine, Fayoum University.

23. Fawzy M, Hassan W, Elbeh K (2012) Prevalence study of psychoactive substance use disorders among students of preparatory and secondary schools in Assiut governorate. MD Thesis, Faculty of Medicine, Assiut University.

24. (2014) World Drug Report. United Nations Office on Drugs and Crime, United Nations, New York, USA

25. CAPMAS, 2015: Egypt Central Agency for Public Mobilization And Statistics". "Egypt in Figures 2015". CAPMAS.

26. Hamdi E, Mamdouh R, Sedrak A, Fathi H, El-Amrosy T (2009) The General Secretariat of Mental Health- $\mathrm{MOH}$ : the National Research on Addiction, Phase 3 - 8 governorates. Research Unit. The General Secretariat of Mental Health- $\mathrm{MOH}$.

27. Hamdi E, Sabry N, Sedrak A, Refaat O (2011) The General Secretariat of Mental Health- $\mathrm{MOH}$ : the National Research on Addiction, Phase 4 - Cairo. Research Unit. The General Secretariat of Mental Health- $\mathrm{MOH}$

28. Hamdi E, Sabry N, Sedrak A, (2014) The General Secretariat of Mental Health$\mathrm{MOH}$ : the National Research on Addiction, Phase 5 - Coastal governorates. Research Unit. The General Secretariat of Mental Health- MOH.

29. Hamdi E, Sabry N, and Sedrak A, (2014) The General Secretariat of Mental Health- $\mathrm{MOH}$ : the National Research on Addiction, Phase 6 - Upper Egypt governorates. Research Unit. The General Secretariat of Mental Health$\mathrm{MOH}$

30. CAPMAS, 2007: Egypt Central Agency for Public Mobilization and Statistics."Population in Censuses by Sex \& Sex Ratio (1882-2006)". Egypt State Information Service.

31. Fureman B, Parikh G, Bragg A, McLellan AT (1990) Addiction Severity Index (5th edn), University of Pennsylvania/Veterans Administration Center for Studies on Addiction, Philadelphia, USA.

32. Hamdi E, Gawad T, Khoweiled A, Sidrak AE, Amer D, et al. (2013) Lifetime prevalence of alcohol and substance use in Egypt: a community survey. Subst Abus 34: 97-104.

33. Okasha A (2001) History of mental health in the Arab world. In: Okasha A Maj M, (Eds) Images in psychiatry: an Arab perspective, World Psychiatric Association, pp. 120

34. Islam: survey, alcohol use in Mideast- Africa $+25 \%$ in 5 years. ANSAmed.

35. Eaton NR, Keyes KM, Krueger RF, Balsis S, Skodol AE, et al. (2012) An 
Citation: Hamdi E, Sabry N, Sedrak A, Khowailed A, Loza N. Sociodemographic Indicators for Substance Use and Abuse in Egypt. J Addiction Prevention. 2016;4(1): 8

invariant dimensional liability model of gender differences in mental disorder prevalence: evidence from a national sample. J Abnorm Psychol 121: 282288.

36. Colpaert K, Vanderplasschen W, Van Hal G, Broekaert E, Schuyten G (2008) Dual substance abusers seeking treatment: demographic, substance-related, and treatment utilization characteristics. J Drug Issues 38: 559-583.

37. Greenfield SF, O'Leary G (1999) Sex differences in marijuana use in the United States. Harv Rev Psychiatry 6: 297-303.

38. Hamdi E, Sabry N, Khoweiled A, Edward A, Enaba D (2013) The Nationa Addiction Research Program: prevalence of alcohol and substance use among women in Cairo. Egypt J Psychiatry 34: 155-163.

39. Johnston LD, O’Malley PM, Miech RA, Bachman JG, Schulenberg JE (2015) Monitoring the Future national survey results on drug use, 1975-2015: Overview, key findings on adolescent drug use. Ann Arbor: Institute for Social Research, The University of Michigan.
40. Stanton MD, Shadish WR (1997) Outcome, attrition, and family-couples treatment for drug abuse: a meta-analysis and review of the controlled, comparative studies. Psychol Bull 122: 170-191.

41. Fals-Stewart W, Birchler GR, O'Farrell TJ (1999) Drug-abusing patients and their intimate partners: dyadic adjustment, relationship stability, and substance use. J Abnorm Psychol 108: 11-23.

42. Maisto SA, O'Farrell TJ, Connors GJ, McKay JR, Pelcovits M (1988) Alcoholics' attributions of factors affecting their relapse to drinking and reasons for terminating relapse episodes. Addict Behav 13: 79-82.

43. Fals-Stewart W, O'Farrell TJ, Birchler GR (2004) Behavioral couples therapy for substance abuse: rationale, methods, and findings. Sci Pract Perspect 2: $30-41$.

44. McInnis OA, Young MM, Saewyc E, Jahrig J, Adlaf E, et al. (2015) Urban and rural student substance Use, Ottawa, Ont: Canadian Centre on Substance Abuse.

45. (2005) United Nations Office on Drug and Crime. Country Profile, Egypt.

\section{Acknowledgements}

The authors are grateful to the help of all the researchers who had contact with the general Egyptian population. Many thanks to the data entry team Mr. Georges, Mr. Michael Georges and Mr. Fadi Adel who made a huge effort to accomplish this work. Last but not least our deepest gratitude goes to the cooperative persons, who accepted to participate in this study and gave of their time to finish the interview voluntarily.

Funding

The "National Addiction Research Program" is a serial community based study, funded by the Egyptian government through the Ministry of Health, general secretariat of mental health. 